\title{
Sjögren's syndrome and sicca symptoms in patients with systemic sclerosis
}

\author{
Alex Magno Coelho Horimoto ${ }^{1}$, Vinicius de Macedo Possamai ${ }^{2}$, Izaias Pereira da Costa ${ }^{3}$ \\ ${ }^{1}$ Rheumatologist MD, PhD Professor of Rheumatology, Medical University of Mato Grosso do Sul, Brazil. ${ }^{2}$ Rheumatologist, Medical \\ University of Mato Grosso do Sul, Brazil. ${ }^{3}$ Rheumatologist, MD, PhD Professor of Rheumatology, Medical University of Mato Grosso do Sul, \\ Brazil.
}

\begin{abstract}
Introduction: Several autoimmune diseases can be accompanied by dysfunction of the salivary glands, regardless of the presence or absence of association with Sjögren's syndrome (SS). A recent study by Maeshima and colleagues found salivary hyposecretion in $58.3 \%$ of patients with various connective tissue diseases, particularly systemic sclerosis (SSc).

Objective: To determine the prevalence of SS and Sicca symptoms in patients with SSc. Assess whether the presence of SS in patients with SSc causes worsening of the disease.

Methods: 69 SSc patients periodically monitored in the rheumatology clinic at NHU/UFMS composed the study. All patients were questioned about sicca symptoms and clinical features. We evaluated the RF levels, ANA, anti-Ro/La.

Results and discussion: 69 SSc patients were enrolled in the study, with average age of 51.2 years, $98.3 \%$ females and $50 \%$ caucasian. Sicca symptoms were present in 48 patients $(69.5 \%)$ with SSc; $43 / 69$ patients (62.3\%) with dry mouth and $46 / 69$ patients (66.7\%) with dry eye. Sicca symptoms were observed in patients with limited and diffuse form of the disease. The antinuclear antibody positivity was $95 \%$ and the rheumatoid factor (RF) was observed in 14 patients (23.3\%). Anti-Ro (SSA) antibodies were detected in 11 patients (15.9\%) and anti-La (SSB) in 6 patients (8.7\%) in this study. Only 16 patients (23.2\%) had true SS, according to the AmericanEuropean Consensus Group on Classification Criteria for Sjögren's syndrome. The findings in the study corroborate data found in literature.

Conclusion: This study confirms that Sicca symptoms are found in a large number of patients with SSc. Sjögren prevalence was observed in $23.2 \%$ of the SSc patients, including patients with limited and diffuse cutaneous subtype of disease.
\end{abstract}

Key words: Sicca syndrome, Sjögren's syndrome, overlap, autoantibodies, systemic sclerosis.

\section{Resumen}

Introducción: Varias enfermedades autoinmunes pueden ir acompañadas de disfunción de las glándulas salivales, independientemente de la presencia 0 ausencia de asociación con el síndrome de Sjögren (SS). Un estudio reciente de Maeshima y sus colegas hallaron hiposecreción salival en el $58,3 \%$ de los pacientes con diversas enfermedades del tejido conectivo, particularmente la esclerosis sistémica (SSc).

Objetivo: Determinar la prevalencia de los síntomas de SS y sicca en pacientes con SSc. Evaluar si la presencia de SS en pacientes con SSc provoca empeoramiento de la enfermedad.

Métodos: 69 pacientes SSc periódicamente monitorizados en la clínica de reumatología en NHU/UFMS formaron parte del estudio. Todos los pacientes fueron interrogados acerca de síntomas sicca y características clínicas. Se evaluaron los niveles de FR, FAN, antiRo/La.

Resultados y discusión: Se incluyeron 69 pacientes SSc en el estudio, con edad promedio de 51,2 años, 98,3\% mujeres y $50 \%$ caucásicos. Los síntomas de Sicca estuvieron presentes en 48 pacientes $(69,5 \%)$ con SSc; $43 / 69$ pacientes $(62,3 \%)$ con boca seca y $46 / 69$ pacientes $(66,7 \%)$ con ojo seco. Síntomas sicca se observaron en pacientes con forma limitada y difusa de la enfermedad. La positividad del anticuerpo antinuclear fue del $95 \%$ y el factor reumatoideo se observó en 14 pacientes $(23,3 \%)$. Anticuerpos Anti-Ro (SSA) se detectaron en 11 pacientes $(15,9 \%)$ y anti-La (SSB) en 6 pacientes (8,7\%) en este estudio. Sólo 16 pacientes $(23,2 \%)$ tenían verdaderas SS, según el Grupo de Consenso Americano-Europeo sobre los criterios de clasificación para el síndrome de Sjögren. Los hallazgos del estudio corroboran los datos encontrados en la literatura.

Conclusión: Este estudio confirma que los síntomas sicca se encuentran en un gran número de pacientes con SSc. Se observó una prevalencia de Sjögren en el $23,2 \%$ de los pacientes con esclerodermia, incluyendo pacientes con subtipo cutáneo limitado y difuso.

Palabras clave: síndrome de Sicca, síndrome de Sjögren, superposición, autoanticuerpos, esclerosis sistémica. 


\section{Introduction}

Systemic sclerosis (SSc) is a complex polygenic disease that manifests in genetically predisposed individuals with exposure to environmental factors ${ }^{1}$. Its pathogenesis is characterized by three major features: vasculopathy of the small vessels, autoantibody production and fibroblast dysfunction leading to an increased deposition of collagen in the extracellular matrix ${ }^{2}$. Clinical manifestations and systemic sclerosis prognosis varies, with most of patients presenting thickening of the skin and a wide internal organ involvement ${ }^{1,2}$. This syndrome can be primary or be present in a context of other connective tissue disease, most commonly rheumatoid arthritis and systemic lupus erythematosus, but may be present in patients with $\mathrm{SSc}^{4}$.

The first report of an association between SSc and Sjögren's syndrome SS was made in 1965 by Bloch and colleagues, who reported this association in 3 patients ${ }^{3}$. Subsequently, several studies have reported the existence of a distinct clinical phenotype in patients with SSc in association with SS, particularly in patients with limited form with positivity for anti-centromere ${ }^{4,5,6,7,8}$. To enhance the complexity of this association, also reports of patients with SS and anti-centromere positivity, but without clinical features of SSc, have been described. This has been considered a distinct clinical variant of primary Sjögren ${ }^{5,7,8}$.

Although sicca symptoms are common in systemic sclerosis patients (60 to $71.2 \%$ ), due to fibrosis of salivary gland ${ }^{3,4,9,10}$, the true SS is present in only 10.3 to $33.9 \%$ of these patients $s^{3,410,11}$. Few data exist describing the association between systemic sclerosis and Sjogren's syndrome, and the data do not show compliance to characterize the SS in SSc patients ${ }^{4,9}$.

Typically, secondary Sjögren's syndrome is different from Sjögren syndrome associated ${ }^{9}$. The SS secondary to rheumatoid arthritis appears to be more a complication, presenting a less aggressive sicca syndrome, anti-Ro/SSA and anti-La/SSB less frequently and the evolution of SS follows the evolution of rheumatoid arthritis ${ }^{3,9}$. On the other hand, Sjögren's syndrome accompanying systemic lupus erythematosus (SLE), or autoimmune thyroiditis shows a serological and clinical pattern similar to the primary SS with the same prevalence of anti-Ro/SSA and anti-La/SSB and the same severity as in primary SS,9.

In this way Sjögren's syndrome seems to be associated with these disorders as an overlap syndrome ${ }^{4}$. Moreover, the association of Sjögren with other autoimmune disease can modify the severity of the autoimmune disease associated with $\mathrm{SS}^{9}$.

It is speculated that the Sjögren syndrome associated with systemic sclerosis could worsen the evolution and prognosis of these patients, however there are few studies describing this association ${ }^{3,9}$.

\section{Objectives}

To determine the prevalence of Sjögren's syndrome and sicca symptoms in patients with SSc.

To evaluate if the presence of Sjögren's syndrome in patients with SSc causes aggravation of the disease, determining if the severity or the clinical manifestations of these diseases change when they are associated.

\section{Methods}

This is an observational and comparative study of 69 patients with SSc treated at the Rheumatology Clinic of UFMS University Hospital. The selection of 69 patients at random, was made from the survey of Medical Records from the University Hospital Rheumatology Department of the Faculty of Medicine of the Federal University of Mato Grosso do Sul (FMUFMS) during the period from February 2014 to March 2015.

\section{Patients were divided into two groups:}

- The first consisting of 16 patients with overlap between Sjögren's syndrome and systemic sclerosis.

- The second consisting of 53 systemic sclerosis patients with or without sicca symptoms but not fulfilling SS criteria.

Patients to be selected should meet the following criteria:

1. For systemic sclerosis:

1.1. Fulfill the new classification criteria ACR/EULAR 2013 for systemic sclerosis ${ }^{12}$.

1.2. In the case of absence of skin thickening, they should fill the early SSc criteria of LeRoy and Medsger $2001^{13}$.

2. For Sjögren's syndrome:

The diagnosis was based on the American-European Consensus Group on Classification Criteria for Sjögren's syndrome ${ }^{14}$.

3. Exclusion:

3.1. Patients who had other associated infectious diseases or malignant neoplasms were excluded.

3.2. Indigenous patients, pregnant women and children were excluded.

Sociodemographic and clinical information needed was obtained from medical records of each patient and supplemented with patients' interviews. At the first visit, demographic and clinical data were collected, including disease duration, year of diagnosis, modified Rodnan skin score ${ }^{15}$, autoantibodies, full clinical examination and current treatment.

All patients were asked about symptoms of ocular and oral dryness by adapting the standard questionnaire for sicca symptoms ${ }^{14}$ (Table 1).

Quantitative variables were analyzed: age, duration 


\begin{tabular}{|l|}
\hline Eye symptoms \\
\hline - Is there daily and persistent eye problems related to dry eye chart for more \\
than three months? \\
- Is there any feeling of sand or ocular burning? \\
- Is there usage of lubricating eye drops more than three times a day? \\
\hline Oral symptoms \\
\hline - Is there any feeling of dry mouth for more than three months? \\
- Is there recurrent or persistent swelling of the salivary glands as an adult? \\
- Do you need to drink liquids to aid in swallowing solid food?
\end{tabular}

Adaptation of the American-European Consensus Group on Classification Criteria for Sjögren's syndrome (VITALI et al., 2002).

\section{Table 1. Standardized questionnaire to sicca syndrome.}

of Raynaud's phenomenon (RP) before diagnosis, disease duration since first non-raynaud symptom and monitoring indices, as well as nominal or ordinal qualitative variables such as sex, ethnia, time of diagnosis and diagnostic criteria. Other manifestations of SSc were also evaluated: cutaneous, vascular, musculoskeletal, cardiopulmonary and kidney manifestations.

Laboratory tests were also analyzed in these patients, the main ones being: ESR, CRP, CPK, Creatinine, C3 and $\mathrm{C} 4$ and immunological tests such as ANA, anti-centromere, anti-DNA topoisomerase I, anti-RNA polymerase 3, rheumatoid factor, anti-Ro (SSA), anti-La (SSB), antiRNP, anti-Sm and anti-Jo. Serum samples from patients properly frozen to $-50^{\circ} \mathrm{C}$ and stored in the Laboratory of the University Hospital of UFMS, were used.

Specific data on the Medsger Severity criteria ${ }^{16}$, Valentini Activity criteria of the disease ${ }^{17}$ and Scleroderma Health Assessment Questionnaire (sHAQ) ${ }^{18}$ were collected in the initial evaluation of the patient.

\section{a - Antinuclear antibodies (ANA)}

Indirect immunofluorescence technique was used for the analysis of ANA with HEp2 cells (Faar technique) as substrate Criteria of the II Brazilian Consensus on Antinuclear factor in Hep-2 cells $(2003)^{19}$ for the interpretation of the results were used.

Sera were considered positive if title was greater than or equal to 160 and diluted until obtain the negativity of the fluorescence.

b - Anti-Sm, anti-RNP, anti-Jo1, anti-Ro (SSA) and anti-La (SSB) antibodies were tested using immunoenzymatic assay technique (ELISA) as previously described by $\mathrm{McClain}^{20}$, using specific substrate kits for each test and following the manufacturer's specifications. (Hemagen Diagnostics, Inc). Values over 3 times cut-off were considered positive.

c - Rheumatoid Factor Research - Nephelometry technique was used and considered positive if the title was greater than $40 \mathrm{UI} / \mathrm{ml}^{21}$.

d - For anti-centromere (ACA) research - the indirect immunofluorescence technique was used with HEp2 cells as substratre and resultad were interpreted according to the criteria of the II Brazilian Consensus on Antinuclear factor in Hep-2 cells $(2003)^{19}$.

e - For anti-DNA topoisomerase 1 (anti-Scl70) testing, - immunoenzymatic assay technique ${ }^{22}$ was used with a specific kit QUANTA Lite TM Scl-70 from INOVA Laboratory (INOVA Diagnostics, Inc., San Diego, CA, USA), following the manufacturer's specifications. It was considered not reactants if $<20$ units, weakly reactants between 20 and 39 units, moderately reactants between 40 and 80 units and highly reactants (high values) if $>80$ units.

f - Anti-RNA polymerase III antibody (anti POL3) - ELISA technique was used as previously described ${ }^{23}$, using a specific kit QUANTA Lite RNA Pol III ELISA from INOVA Laboratory (INOVA Diagnostics, Inc., San Diego, CA, USA), following the manufacturer's specifications. Values were considered negative $<20$ units, weakly reactants between 20 and 39 units, moderately reactants between 40 and 80 units and strongly reagents (higher values) if $>80$ units.

\section{Statistical analysis}

Comparison between patients with SSc associated with SS, with those without this association, in relation to the quantitative variables evaluated in this study, was performed using t-student test.

Chi-square test was used to assess the association between the results for Sjögren's Syndrome (present or absent), with qualitative variables measured in this study. The results of the other variables assessed in this study were presented in the form of descriptive statistics or in tables and graphs. Statistical analysis was performed using the "software" SPSS, version 20.0, assuming a significance level of $5 \%{ }^{24}$.

\section{Results}

Results related to epidemiological data and monitoring indexes in SSc patients with Sjögren's syndrome present or absent, are shown in Table 2.

There was no significant difference between patients with SSc and SS present or absent in relation to the quantitative variables age, RP time prior to diagnosis, disease duration after diagnosis and monitoring indexes ( $\mathrm{t}$-student test, $\mathrm{p}$ values ranging from 0.411 and 0.938 ). There was also no association between the presence of SS and the nominal or ordinal qualitative variables sex, race, clinical form and time of diagnosis (chi-square test, $\mathrm{p}$ value ranging between 0.197 and 0.655 ).

Table 3 shows the results for the cutaneous, vascular and musculoskeletal manifestations in SSc patients with Sjögren's syndrome present or absent. There was no association between clinical manifestations and the result 


\begin{tabular}{|c|c|c|c|}
\hline \multirow[t]{2}{*}{ Variable } & \multicolumn{2}{|c|}{ Sjögren's syndrome } & \multirow[t]{2}{*}{ p value } \\
\hline & Present & Absent & \\
\hline \multicolumn{4}{|l|}{ Epidemiological data } \\
\hline Age & $52.25 \pm 2.56$ & $51.98 \pm 1.71$ & \multirow[t]{2}{*}{0.938} \\
\hline \multicolumn{3}{|l|}{ Sex } & \\
\hline Male & $0.0(0)$ & $1.9(1)$ & \multirow[t]{2}{*}{0.578} \\
\hline Female & $100.0(16)$ & $98.1(52)$ & \\
\hline \multicolumn{4}{|l|}{ Color } \\
\hline White & $31.3(5)$ & $52.8(28)$ & \multirow{3}{*}{0.197} \\
\hline Brown & $56.3(9)$ & $43.4(23)$ & \\
\hline Black & $12.4(2)$ & $3.8(2)$ & \\
\hline \multicolumn{4}{|l|}{ Disease duration } \\
\hline Less than 5 years & $18.8(3)$ & $26.4(14)$ & \multirow{3}{*}{0.655} \\
\hline Between 5 and 10 years & $43.8(7)$ & $47.2(25)$ & \\
\hline More than 10 years & $37.4(6)$ & $26.4(14)$ & \\
\hline $\begin{array}{l}\text { Duration of Raynaud's } \\
\text { phenomenon before } \\
\text { diagnosis (years) }\end{array}$ & $4.63 \pm 2.18$ & $3.96 \pm 0.98$ & 0.758 \\
\hline $\begin{array}{l}\text { Disease duration } \\
\text { after diagnosis }\end{array}$ & $10.06 \pm 1.48$ & $9.36 \pm 0.87$ & 0.694 \\
\hline \multicolumn{4}{|l|}{ Clinical form } \\
\hline Limited & $43.8(7)$ & $49.1(26)$ & \multirow{4}{*}{0.359} \\
\hline Diffuse & $43.8(7)$ & $28.3(15)$ & \\
\hline Early systemic sclerosis & $0.0(0)$ & $13.2(7)$ & \\
\hline Overlap & $12.4(2)$ & $9.4(5)$ & \\
\hline \multicolumn{4}{|l|}{ Monitoring index } \\
\hline SHAQ & $0.67 \pm 0.09$ & $0.61 \pm 0.06$ & 0.603 \\
\hline Medsger's Severity scale & $5.06 \pm 0.56$ & $4.87 \pm 0.41$ & 0.811 \\
\hline Valentini's Activity scale & $2.69 \pm 0.26$ & $2.36 \pm 0.20$ & 0.411 \\
\hline
\end{tabular}

Results are presented as mean \pm standard error of the mean or relative frequency (absolute frequency). ${ }^{*} \mathrm{P}$ value in the Student $\mathrm{t}$ test or chi-square test. SHAQ: Health Assessment Questionnaire in systemic sclerosis.

Table 2. Distribution of patients evaluated in this study and results of the epidemiological data and monitoring indexes in SSc patients according to Sjögren's syndrome presence or absence.

(present or absent) for the Sjögren syndrome in SSc patients (chi-square test, $p$ value ranging between 0.216 and 0.951). There was also no significant difference between patients with SS present or absent in relation to skin score (t-student test, $\mathrm{p}=0.816$ ).

Frequency of gastrointestinal, cardiopulmonary and kidney manifestations in patients with SSc and Sjögren's syndrome present or absent, are shown in Table 4. There was no association between the presence or absence for the SS and the variables related to gastrointestinal, cardiopulmonary and kidney manifestations observed in patients evaluated in this study (chi-square test, $\mathrm{p}$ value ranging between 0.141 and 0.973 ).

Laboratory tests in SSc patients with Sjögren's syndrome present or absent, are shown in Table 5. We only found differences in the percentage of patients with positive anti-Ro (SSA) and anti-La (SSB), which was higher in patients with SS associated $(0.0 \%-\mathrm{N}=0$ - chisquare test, $\mathrm{p}=<0.001)$. For other laboratory tests, such as anti-Sm, anti RNP, Anti-Jo1, ESR, CRP, CPK, Cr, C3, C4 and hand $\mathrm{Rx}$, there was no difference between both groups (student $\mathrm{t}$ test, $\mathrm{p}$ value ranging between 0.177 and 0.941 ).

\begin{tabular}{|c|c|c|c|}
\hline \multirow[t]{2}{*}{ Variable } & \multicolumn{2}{|c|}{ Sjögren's syndrome } & \multirow[t]{2}{*}{ p value } \\
\hline & Present & Absent & \\
\hline \multicolumn{4}{|l|}{ Cutaneous manifestations } \\
\hline \multicolumn{4}{|l|}{ Calcinosis } \\
\hline Yes & $40.0(4)$ & $17.0(9)$ & \multirow{2}{*}{0.723} \\
\hline No & $60.0(12)$ & $83.0(44)$ & \\
\hline \multicolumn{4}{|l|}{ Hands } \\
\hline Without changes & $6.2(1)$ & $24.5(13)$ & \multirow{2}{*}{0.216} \\
\hline With changes & $93.8(15)$ & $75.5(40)$ & \\
\hline \multicolumn{4}{|c|}{ Cutaneous involvement in hands $(n=54)$} \\
\hline Puffy fingers & $40.0(6)$ & $25.6(10)$ & \multirow{3}{*}{0.324} \\
\hline Indurative phase & $40.0(6)$ & $33.3(13)$ & \\
\hline Atrophic stage & $20.0(3)$ & $41.1(16)$ & \\
\hline Modified Rodnan's score & $12.25 \pm 1.39$ & $12.77 \pm 1.16$ & 0.816 \\
\hline \multicolumn{4}{|l|}{ Vascular manifestations } \\
\hline \multicolumn{4}{|l|}{ RP } \\
\hline Objective & $81.2(13)$ & $62.3(33)$ & \multirow{2}{*}{0.267} \\
\hline Subjective & $18.8(3)$ & $37.7(20)$ & \\
\hline \multicolumn{4}{|l|}{ Micro scars } \\
\hline Yes & $18.8(3)$ & $22.6(12)$ & \multirow{2}{*}{0.741} \\
\hline No & $81.2(13)$ & $77.4(41)$ & \\
\hline \multicolumn{4}{|l|}{ Active ulcers } \\
\hline Yes & $6.2(1)$ & $9.4(5)$ & \multirow{2}{*}{0.692} \\
\hline No & $93.8(15)$ & $90.6(48)$ & \\
\hline \multicolumn{4}{|c|}{ Necrosis or finger amputation } \\
\hline Yes & $12.5(2)$ & $7.5(4)$ & \multirow{2}{*}{0.912} \\
\hline No & $87.5(14)$ & $92.5(49)$ & \\
\hline \multicolumn{4}{|l|}{ Telangiectasia } \\
\hline Yes & $75.0(12)$ & $67.9(36)$ & \multirow{2}{*}{0.819} \\
\hline No & $25.0(4)$ & $32.1(17)$ & \\
\hline \multirow{2}{*}{\multicolumn{4}{|c|}{ Musculoskeletal manifestations }} \\
\hline \multicolumn{3}{|l|}{ Arthritis/synovitis } & \\
\hline Yes & $50.0(8)$ & $32.1(17)$ & \multirow{2}{*}{0.312} \\
\hline No & $50.0(8)$ & $67.9(36)$ & \\
\hline Contracture in flexion of $h$ & & & \\
\hline Yes & $6.2(1)$ & $13.2(7)$ & 0752 \\
\hline No & $93.8(15)$ & $86.8(46)$ & 0.152 \\
\hline Tendon friction rubs & & & \\
\hline Yes & $6.2(1)$ & $1.9(1)$ & 0051 \\
\hline No & $93.8(15)$ & $98.1(52)$ & 0.951 \\
\hline Muscle weakness & & & \\
\hline Yes & $40.0(4)$ & $11.3(6)$ & 0230 \\
\hline No & $60.0(12)$ & $88.7(47)$ & 0.339 \\
\hline Muscle atrophy & & & \\
\hline Yes & $6.2(1)$ & $11.3(6)$ & 200 \\
\hline No & $93.8(15)$ & $88.7(47)$ & 0.907 \\
\hline
\end{tabular}

Results are presented as mean \pm standard error of the mean or relative frequency (absolute frequency). ${ }^{*} \mathrm{P}$ value in the Student $\mathrm{t}$ test or chi-square test. RP: Raynaud's phenomenon.

Table 3. Distribution of patients evaluated in this study and results for the cutaneous manifestations, vascular and musculoskeletal in SSc patients with Sjögren's syndrome present or absent.

Over the whole SSc group ( $\mathrm{n}=69), 66.7 \%$ patients had dry eye and $62.3 \%$ had dry mouth. As expected, all patients with real overlap between SSc and Sjögren's syndrome $(n=16)$ had dry eye and dry mouth Data presented in Table 6.

\section{Discussion}

Sicca symptoms are common in patients with systemic sclerosis (68\%-71.2\%), and usually explained by fibrosis of exocrine glands in patients with diffuse disease and extensive systemic involvement ${ }^{3,10,11}$. Association between 


\begin{tabular}{|c|c|c|c|}
\hline \multirow[t]{2}{*}{ Variable } & \multicolumn{2}{|c|}{ Sjögren's syndrome } & \multirow[t]{2}{*}{ p value } \\
\hline & Present & Absent & \\
\hline \multicolumn{4}{|c|}{ Gastrointestinal manifestations } \\
\hline \multicolumn{4}{|l|}{ Esophagus involvement } \\
\hline Yes & $81.3(13)$ & $69.8(37)$ & \multirow{2}{*}{0.563} \\
\hline No & $18.8(3)$ & $30.2(16)$ & \\
\hline \multicolumn{4}{|l|}{ Other GI manifestations } \\
\hline GERD & $25.0(4)$ & $22.6(12)$ & 0.845 \\
\hline Esophagitis & $31.3(5)$ & $20.8(11)$ & 0.593 \\
\hline Gastritis & $31.3(5)$ & $22.6(12)$ & 0.712 \\
\hline Esophageal hypotonia & $18.8(3)$ & $15.1(8)$ & 0.726 \\
\hline Esophageal dilatation & $12.5(2)$ & $5.7(3)$ & 0.708 \\
\hline \multicolumn{4}{|c|}{ Cardiopulmonary manifestations } \\
\hline \multicolumn{4}{|l|}{ FVC - classification } \\
\hline$>80 \%$ & $50.0(8)$ & $56.6(30)$ & \multirow{4}{*}{0.796} \\
\hline Between 70 and $80 \%$ & $31.3(5)$ & $32.1(17)$ & \\
\hline Between 50 and $69 \%$ & $12.5(2)$ & $9.4(5)$ & \\
\hline$<50 \%$ & $6.3(1)$ & $1.9(1)$ & \\
\hline \multicolumn{4}{|l|}{ High resolution lung CT } \\
\hline Normal & $31.3(5)$ & $54.7(29)$ & \multirow{2}{*}{0.174} \\
\hline Abnormal & $68.8(11)$ & $45.3(24)$ & \\
\hline \multicolumn{4}{|l|}{ Findings in CT $(n=35)$} \\
\hline Fibrosis & $63.6(7)$ & $70.8(17)$ & \multirow{2}{*}{0.973} \\
\hline "Ground glass" pattern & $36.4(4)$ & $29.2(7)$ & \\
\hline ECo PSAP & $39.50 \pm 4.57$ & $32.83 \pm 3.42$ & 0.325 \\
\hline \multicolumn{4}{|l|}{ Echocardiogram } \\
\hline Normal & $71.4(9)$ & $45.3(24)$ & \multirow{2}{*}{0.628} \\
\hline Abnormal & $28.6(7)$ & $54.7(29)$ & \\
\hline \multicolumn{4}{|c|}{ Findings in echocardiography $(n=31)$} \\
\hline Valvulopathy & $31.3(5)$ & $26.4(14)$ & 0.952 \\
\hline Concentric LVH & $0.0(0)$ & $18.9(10)$ & 0.141 \\
\hline LV diastolic dysfunction & $12.5(2)$ & $15.1(8)$ & 0.796 \\
\hline PAH mild or moderate & $18.8(3)$ & $11.3(6)$ & 0.727 \\
\hline Pericarditis & $18.8(3)$ & $7.5(4)$ & 0.407 \\
\hline \multicolumn{4}{|l|}{ Renal manifestations } \\
\hline \multicolumn{4}{|l|}{ Renal crisis } \\
\hline Yes & $0.0(0)$ & $1.9(1)$ & \multirow{2}{*}{0.580} \\
\hline No & $100.0(16)$ & $98.1(52)$ & \\
\hline
\end{tabular}

Results are presented as mean \pm standard error of the mean or relative frequency (absolute frequency). * $\mathrm{P}$ value in the Student $\mathrm{t}$ test or chi-square test. Gl: gastrointestinal; GERD: gastroesophageal reflux disease; FVC: pulmonary functional vital capacity; ECO PSAP: estimated pulmonary artery pressure by transthoracic echocardiography; LVH: left ventricular hypertrophy; LV: left ventricle; PAH: pulmonary arterial hypertension.

Table 4. Results related to gastrointestinal, cardiopulmonary and renal manifestations in SSc patients with Sjögren's syndrome present or absent.

SSc and decrease of lachrymal or salivary secretion is a relatively common finding ${ }^{10,25}$. We found similar rates to those described in the literature, with occurrence of dry eye in $66.7 \%$ and dry mouth in $62.3 \%$ of patients with SSc (with or without association with Sjögren).

Kobak and colleagues observed, as in this study, that sicca symptoms were found in all patients with SS and SSc overlapping, while the group of patients with SSc alone had a statistically significant lower frequency of dry eye and dry mouth ${ }^{10}$.

Drosos and colleagues detected histopathological changes compatible with SS by biopsy of the labial salivary gland in $20.5 \%$ of the SSc patients, although in most cases the decrease in the secretory function is caused by submucosal fibrosis and "genuine” Sjögren's syndrome can not be often present in SSc patients ${ }^{26}$. In our case, Sjogren's

\begin{tabular}{|c|c|c|c|}
\hline \multirow[t]{2}{*}{ Variable } & \multicolumn{2}{|c|}{ Sjögren's syndrome } & \multirow[t]{2}{*}{ p value } \\
\hline & Present & Absent & \\
\hline ESR & $34.94 \pm 6.13$ & $26.57 \pm 2.82$ & 0.177 \\
\hline CRP & $13.92 \pm 4.34$ & $12.04 \pm 2.96$ & 0.751 \\
\hline CPK & $136.06 \pm 42.81$ & $130.64 \pm 14.73$ & 0.879 \\
\hline Creatinine & $0.74 \pm 0.03$ & $0.75 \pm 0.03$ & 0.894 \\
\hline C3 & $125.88 \pm 7.19$ & $132.23 \pm 3.65$ & 0.414 \\
\hline C4 & $31.44 \pm 2.56$ & $34.26 \pm 1.30$ & 0.308 \\
\hline \multicolumn{4}{|l|}{ Anti-Ro } \\
\hline Positive & $68.8(11)^{\mathrm{a}}$ & $0.0(0)^{\mathrm{b}}$ & \multirow{2}{*}{$<0.001$} \\
\hline Negative & $31.3(5)^{b}$ & $100.0(53)^{\mathrm{a}}$ & \\
\hline \multicolumn{4}{|l|}{ Anti-La } \\
\hline Positive & $37.5(6)^{\mathrm{a}}$ & $0.0(0)^{b}$ & \multirow{2}{*}{$<0.001$} \\
\hline Negative & $62.5(10)^{b}$ & $100.0(53)^{\mathrm{a}}$ & \\
\hline \multicolumn{4}{|l|}{ Anti-Sm } \\
\hline Positive & $0.0(0)$ & $1.9(1)$ & \multirow{2}{*}{0.580} \\
\hline Negative & $100.0(16)$ & $98.1(52)$ & \\
\hline \multicolumn{4}{|l|}{ Anti-RNP } \\
\hline Positive & $12.5(2)$ & $13.2(7)$ & \multirow{2}{*}{0.941} \\
\hline Negative & $87.5(14)$ & $86.8(46)$ & \\
\hline \multicolumn{4}{|l|}{ Anti-Jo 1} \\
\hline Positive & $6.3(1)$ & $3.8(2)$ & \multirow{2}{*}{0.670} \\
\hline Negative & $93.8(15)$ & $96.2(51)$ & \\
\hline \multicolumn{4}{|l|}{ Hands X-rays } \\
\hline Normal & $37.5(6)$ & $60.4(32)$ & \multirow{2}{*}{0.185} \\
\hline Abnormal & $62.5(10)$ & $39.6(21)$ & \\
\hline \multicolumn{4}{|c|}{ Findings on hands $X$-rays $(n=31)$} \\
\hline Calcinosis & $60.0(6)$ & $38.1(8)$ & \multirow{2}{*}{0.448} \\
\hline Resorption (distal phalange) & $40.0(4)$ & $61.9(13)$ & \\
\hline
\end{tabular}

Results are presented as mean \pm standard error of the mean or relative frequency (absolute frequency). ${ }^{*} P$ value in the Student $t$ test or chi-square test. Different letters on the line indicate significant differences between patients with and without Sjögren's syndrome (chi-square test, $\mathrm{p}<0.05$ ). ESR: erythrocyte sedimentation rate; CRP: $\mathrm{C}$ reactive protein; $\mathrm{CPK}$ creatine phosphokinase; $\mathrm{C} 3$ : C3 fraction of the complement; C4: fraction of complement C4; $\mathrm{X}$-rays: radiography.

Table 5. Other results of the laboratory tests in SSc patients with Sjögren's syndrome present or absent.

\begin{tabular}{|l|c|c|c|c|}
\hline \multirow{2}{*}{ Symptom } & \multicolumn{2}{|c|}{ Sjögren's syndrome } & \multirow{2}{*}{ p value } & Total \\
\cline { 2 - 3 } & Present & Absent & & \\
\hline Dry mouth & & & \\
\hline Yes & $100.0(16)^{\mathrm{a}}$ & $50.9(27)^{\mathrm{b}}$ & \multirow{2}{*}{0.001} & $62.3(43)$ \\
\hline No & $0.0(0)^{\mathrm{b}}$ & $49.1(26)^{\mathrm{a}}$ & & $37.7(26)$ \\
\hline Total & $23.2(16)$ & $76.8(53)$ & & $100.0(69)$ \\
\hline Dry eyes & $100.0(16)^{\mathrm{a}}$ & $56.6(40)$ & \multirow{2}{*}{0.003} & $66.7(46)$ \\
\hline Yes & $0.0(0)^{\mathrm{b}}$ & $43.4(23)$ & & $33.3(23)$ \\
\hline No & $23.2(16)$ & $76.8(53)$ & & $100.0(69)$ \\
\hline Total & &
\end{tabular}

The results are presented as relative frequency (absolute frequency). ${ }^{*} \mathrm{P}$ of chi-square test.

Table 6. Distribution of SSc patients evaluated in this study, according to the association with Sjögren's syndrome and the presence of xerostomia or xerophthalmia.

syndrome was found in patients with SSc diffuse disease and also in patients with limited SSc with long period of disease evolution.

Maeshima and colleagues describe that autoimmune diseases can be accompanied by dysfunction of the salivary glands regardless of the presence or absence of association with $\mathrm{SS}^{25}$. The authors found salivary secretion disorders in $58.3 \%$ of patients with several diseases of connective tissue, excluding patients with primary SS. Among patients 
who did not have secondary association with SS, the SSc was the disease that most closely correlated with salivary dysfunction ${ }^{25}$. Corroborating these findings, this study observed a similar frequency of $62.3 \%$ of dry mouth in patients with SSc without SS.

However, only about 14 to $20 \%$ of patients meet diagnostic criteria for Sjogren's syndrome ${ }^{3,11}$. Published data about the true association between SS in SSc are extremely divergent and inconsistent. Perhaps the main reason for this discrepancy is the use of various criteria for the diagnosis of SS in different studies ${ }^{10}$. We observed a prevalence of Sjögren in $23.2 \%$ of patients with SSc, through the American-European Consensus Group on Classification Criteria for Sjögren's syndrome ${ }^{14}$. Another study found the prevalence of SS in $10.3 \%$ of 165 patients with SSc. In these patients the SS was the second most frequent overlap, accounting for $42.5 \%$ of all overlap syndromes ${ }^{11}$.

In general, the SS was found more frequently in patients with the limited form of SSc, which was attributed to specific autoimmunity mediated by B lymphocytes with predominant production of anti-centromere antibody ${ }^{10}$. However, in our study, vast majority of patients were both diffuse or limited form of the disease with long evolution time and two patients also had overlap with rheumatoid arthritis.

Several cases of overlap between SSc, SS and other autoimmune diseases are reported in the literature ${ }^{27}$, including patient with anti synthetase syndrome with positivity for anti isoleucyl-tRNA synthetase (antiOJ antibody), with severe systemic involvement and pulmonary, esophageal, skin, muscle and microvascular impairment ${ }^{28}$. However all of our patients with SSc and SS were negative for antibodies to anti synthetase syndrome (anti-Jo1) and anti-OJ was not dosed in our research.

Other common association is between SS, SSc particularly of the limited subtype CREST (calcinosis, Raynaud, esophageal dysmotility, sclerodactyly, and telangiectasia) and primary biliary cirrhosis (PBC). This association may also include autoimmune thyroiditis ${ }^{27,29,30}$. A case of overlaping of SS, SSc and portal hypertension without hepatic cirrhosis has been reported. Furthermore already been reported patient case with SS, SSc and idiopathic portal hypertension without hepatic cirrhosis ${ }^{31}$.

These similar results suggest that the association between these autoimmune diseases is not merely accidental, but share immunological abnormalities including production of autoantibodies ${ }^{29}$. Salliot and colleagues highlight that the association of SS with SSc reflects the dissemination of autoimmunity, since a third autoimmune disorder (PBC) was present in $40 \%$ of cases 9 . For example, the high incidence of patients with PBC in SS can be partially explained by the presence of a common antigen in bile ductal epithelium, and salivary gland ${ }^{29}$. One study from the Mayo Clinic evaluating 113 patients with PBC, found that $84 \%$ of patients had at least one other autoimmune disorder, and $18 \%$ was $\mathrm{SSc}^{27}$. But none of our patients presented $\mathrm{PBC}$.

A rare association of patients with $\mathrm{SSc}$ and SS overlapping associated with psoriasis vulgaris has been described in the literature ${ }^{32}$. The association between psoriasis and SSc is already rare, with a total of 13 patients reported in the literature ${ }^{32}$. We also did not observe this association in our patients.

Other factors that can generate diagnostic confusion are due to reports of a subgroup of patients with primary SS and positive anti-centromere antibodies (ACA), recognized as having intermediate characteristics between $\mathrm{SS}$ and $\mathrm{SSc}^{7,8}$. The prevalence of ACA in patients with primary SS is conflicting, with initial reports reporting frequency between $16-27 \%$ and most recent publications found lower prevalence, between $2-7 \%{ }^{6}$. However, only about one quarter of patients who initially presented with these characteristics developed SSc, despite a long period of follow-up ${ }^{3,8}$.

Literature suggests that ACA antibody should be tested in patients with primary SS and Raynaud's phenomenon, since these patients may have coexistence with limited $\mathrm{SSc}^{3}$.

In these patients with SS and positive ACA, sicca manifestations were observed in variable frequency from $13.6 \%$ to $37 \%$ and one of the studies demonstrated infiltration of mononuclear cells in minor salivary gland biopsies without fibrotic changes, probably related solely to the SS 5 . Wonders whether these patients with SS and positive results for ACA merely represent a subgroup of patients with SS or a transitional phase for evolving the $\mathrm{SSc}^{8}$.

It was previously reported that the phenotype of various autoimmune diseases may be altered in those patients associated with Sjögren's syndrome ${ }^{10}$.

Baldini and colleagues emphasize that this subgroup of patients with SS and SSc overlap with positive ACA exhibit mild clinical involvement, with less cardiovascular, gastrointestinal and pulmonary fibrosis involvement? although a greater risk of non-Hodgkin's lymphoma development $t^{6,733}$. None of our patients with SS and SSc developed lymphoma in this short period of observation.

Indeed, in the literature there is a general agreement that in patients with overlap syndrome, SSc is generally less severe while the glandular manifestations of SS tend to be fully manifest ${ }^{3,4,6,7,9,10,11}$. In other words, secondary or associated SS seems to have a favorable impact on the prognosis of patients with SSc.

Kobak and colleagues found in the patient group with overlap between SS and SSc a lower frequency of fibrosis and pulmonary hypertension ${ }^{10}$. Salliot and colleagues found in the patient group with overlapping the same milder symptoms, and lower frequency of scleroderma renal crisis?. However, it was not possible to observe a statistically lower incidence of arthritis, vascular disease, gastrointestinal, renal or pulmonary involvement in our patients.

Bournia and colleagues concluded that patients with SS with ACA-positive represent a subset of patients with an 
intermediate phenotype between primary SS and SSc, with a slight tendency to evolve $\mathrm{SSc}^{7}$.

García-Carrasco and colleagues found the presence of Raynaud's phenomenon in $13 \%$ of patients with primary SS, and this group of patients presented a higher incidence of extra glandular manifestations such as arthritis and vasculitis, as well as autoantibodies (anti-Ro and anti-La) ${ }^{34}$. Especially, some patients with primary SS with positive ACA, showed changes in the nailfold capillaroscopy, although no clinical evidence of association with $\mathrm{SSc}^{34}$. Accordingly, we observed that Raynaud's phenomenon was a prevalent and important manifestation in our patients with SSc and SS, as was observed in $81.3 \%$ of these patients, against $62.3 \%$ of patients with SSc alone.

Previous findings suggest that anti-Ro and anti-La autoantibodies may be specific serological markers of a SS overlay in SSc patients ${ }^{10}$. We found anti-Ro in $68.8 \%$ and anti-La in $37.5 \%$ of patients with SSc and SS. However, low titers of this antibody did not change the severity of arthritis, neuropathy or cryoglobulinemia in patients with $\mathrm{SSc}$ associated to $\mathrm{SS}^{11}$.

Although there are still no reliable markers of overlap between SSc and SS, there is consensus in the literature of the usefulness of anti-Ro and anti-La ${ }^{4,5,6,6,8,10,11}$. Wuttge and colleagues suggest that in an early SSc stage, a very high activity type I interferon would be related to the development of overlap syndromes in these patients, such as SS and lupus, with formation of antibodies against extractable core antigens (Ro and La), immunoglobulin G and cytopenias elevation ${ }^{35}$.

\section{Conclusion}

We conclude that the presence of Sjögren's syndrome did not affect positively or negatively the severity or the clinical manifestations observed in patients with SSc.

We observed a prevalence of Sjögren in $23.2 \%$ of patients with SSc, both in patients with limited or diffuse SSc, the principal clinical manifestation was the Raynaud's phenomenon, Anti-Ro antibodies were detected in 11 patients $(15.9 \%)$ and anti-La in 6 patients $(8.7 \%)$ in this SSc group.

Sicca symptoms were very common in this study: $66.7 \%$ of SSc patients complained of dry eye and $63.3 \%$ of dry mouth.

\section{Bibliographic references}

1. Herrick AL, Worthington J. Genetic epidemiology Systemic sclerosis. Arthritis Res 2002;4:165-8.

2. Varga J, Abraham D. Systemic sclerosis: a prototypic multisystem fibrotic disorder. J Clin Invest 2007;117:557-67.

3. Ramos-Casals M, Brito-Zerón P, Font J. The overlap of Sjögren's syndrome with other systemic autoimune diseases. Semin Arthritis Rheum 2007;36:246-55.

4. Avouac J, Sordet C, Depinay C, Ardizonne M, VacherLavenu MC, Sibilia J et al. Systemic sclerosis-associated Sjögren's syndrome and relationship to the limited cutaneous subtype: results of a prospective study of sicca syndrome in 133 consecutive patients. Arthritis Rheum 2006;54:2243-9.

5. Miyawaki S, Asanuma H, Nishiyama S, Yoshinaga Y. Clinical and serological heterogeneity in patients with anti-centromere antibodies. J Rheumatol 2005; 32:148894.

6. Gulatti D, Kushner I, File E, Magrey M. Primary Sjögren's syndrome with anti-centromere antibodies - a clinically distinct subset. Clin Rheumatol 2010; 29:78991.

7. Baldini C, Mosca M, Della Rossa A, Pepe P, Notarstefano C, Ferro F et al. Overlap of ACA-positive systemic sclerosis and Sjögren's syndrome: a distinct clinical entity with mild organ involvement buta $t$ high risk of lymphoma. Clin Exp Rheumatol 2013;31:272-80.

8. Bournia VKK, Diamanti KD, Vlachoyannopoulos PG, Moutsopoulos HM. Anti-centromere antibody positive Sjögren's syndrome: a retrospective descriptive analysis. Arthritis Res Ther 2010;12:R47 (http:// arthritis-research.com/content/12/2/R47).

9. Salliot C, Mouthon L, Ardizzone M, Sibilia J, Guillevin L, Gottenberg JE et al. Sjögren's syndrome is associated with and not secondary to systemic sclerosis. Rheumatology (Oxford) 2007;46:321-6.

10. Kobak S, Oksel F, Aksu K, Kabasakal Y. The frequency of sicca symptons and Sjögren's syndrome in patients with systemic sclerosis. Intern J Rheum Dis 2013;16:8892.

11. Balbir-Gurman A, Braun-Moscovici Y. Scleroderma overlap syndrome. Israel Med Assoc J 2011;13:14-20.

12. Hoogen F, Khanna D, Fransen J, Johnson SR, Baron M, Tyndall A et al. 2013 classification criteria for systemic sclerosis: an American college of rhematology/ European league against rheumatism collaborative initiative. Ann Rheum Dis 2013;72:1747-55.

13. LeRoy EC, Medsger Jr. TA. Criteria for the Classification of Early Systemic Sclerosis. J Rheumatol 2001;28:1573-6.

14. Vitali C, Bombardieri S, Jonsson R, Moutsopoulos HM, Alexander EL et al. Classification criteria for Sjögren's syndrome: a revised version of the European criteria proposed by the American-European Consensus Group. Ann Rheum Dis 2002;61:554-558.

15. Valentini G, D'Angelo S, Rossa AD, Bencivelli W, Bombardieri S. European Scleroderma Study Group to define disease activity criteria for systemic sclerosis. IV. Assessment of skin thickening by modified Rodnan skin score. Ann Rheum Dis 2003;62:904-5.

16. Medsger Jr TA, Bombardieri S, Czirjak L, Scorza R, Della Rossa A, Bencivelli W. Assessment of disease severity and prognosis. Clin Exp Rheumatol 2003;21:42-6.

17. Valentini G, Della Rossa A, Bombardieri S, Bencivelli 
W, Silman AJ, D'Angelo S et al. European multicentre study to define disease activity criteria for systemic sclerosis. II. Identification of disease activity variables and development of preliminar activity indexes. Ann Rheum Dis 2001;60:592-8.

18. Rannou F, Poiraudeau S, Berezné A, Baubet T, LeGuern V, Cabane J et al. Assessing disability and quality of life in systemic sclerosis: construct validities of the Cochin hand function scale, health assessment questionnaire (HAQ), systemic sclerosis HAQ, and medical outcomes study 36-item short form health survey. Arthritis Rheum 2007;57:94-102.

19. Dellavance A, Gabriel Jr. A, Cintra AFU, Ximenes AC, Nuccitelli B, Tabilerti BH et al. II Consenso Brasileiro de Fator Antinuclear em células Hep-2. Rev Bras Reumatol 2003;43:129-40.

20. McClain MT, Ramsland PA, Kaufman KM, James JA. Anti-Sm autoantibodies in systemic lupus target highly basic surface structures of complexed spliceosomal autoantigens. J Immunol 2002;168:2054-62.

21. Adams LE, Spencer-Green G, Donovan-Brand R, Mcenergy P, Hayden L, Hess EV et al. Comparison of four rheumatoid fator assays. Clin Labor Sci (Washington, DC) 1988;1:362-5.

22. Sato S, Hamaguchi Y, Hasegawa M, Takehara K. Clinical significance of anti-topoisomerase I antibody levels determined by ELISA in systemic sclerosis. Rheum 2001;40:1135-40.

23. Codullo V, Morozzi G, Bardoni A, Salvini R, Deleonardi $G$, Pità $\mathrm{O}$ et al. Validationof a new immuno enzymatic method to detect antibodies to RNA polymerase III in systemic sclerosis. Clin Exp Rheumatol 2007;25:373-7.

24. SHOTT, S. Statistics for health professionals. London: W.B. Saunders Company 1990.

25. Maeshima E, Furukawa K, Maeshima S, Koshiba H, Sakamoto W. Hyposalivation in autoimune diseases. Rheumatol Int 2013;33:3079-82.

26. Szigeti N, Fábián G, Czirják L. Fatal scleroderma renal crisis caused by gastrointestinal bleeding in a patient with scleroderma, Sjögren's syndrome and primary biliaty cirrhosis overlap. JEADV 2002;16:276-9.

27. Anaya JM, Tobon GJ, Veja P, Castiblanco J. Autoimmune disease aggregation in families with primary Sjögren's syndrome. J Rheumatol 2006; 33:2227-34.

28. Hervier B, Lambert M, Hachulla E, Muset L, Benvniste $\mathrm{O}$, Piette JC et al. Anti-synthetase syndrome positive for anti-isoleucyl-tRNA synthetase antibodies: an unusual case overlapping with systemic sclerosis and Sjögren's syndrome. Rheumatology 2011;50:1175-6.

29. Nakamura T, Higashi S, Tomoda K, Tsukano M, Sugi K. Primary biliary cirrhosis (PBC) - CREST overlap syndrome with coexistence of Sjögren's syndrome and thyroid dysfunction. Clin Rheumatol 2007;26:596-600.

30. Hanafusa T, Igawa K, Kotobuki Y, Kitaba S, Tani M, Katayama I. Systemic lymphadenopathy with systemic sclerosis and Sjogren's syndrome: a case report. Jap
Dermatol Assoc 2012;18:124-5.

31. Kogawa H, Migita K, Ito M, Takii Y, Daikoku M, Nakao $\mathrm{M}$ et al. Idiopathic portal hypertension associated with systemic sclerosis and Sjögren's syndrome. Clin Rheumatol 2005;24:544-7.

32. Yamamoto T, Nishioka K. Coexistence of psoriasis vulgaris, systemic sclerosis and anular erytjema in association with Sjögren's syndrome. J Dermatol 2004;31:69-72.

33. Mellemkjaer L, Pfeiffer RM, Engels EA, Gridley G, Wheeler W, Hemminki K et al. Autoimmune disease in individuals and close Family members and susceptibility to non-Hodgkin's lymphoma. Arthritis Rheum 2008;58:657-66.

34. García-Carrasco M, Sisó A, Ramos-Casals M, Tosas J, delaRed G, Gil V et al. Raynaud's phenomenon in primary Sjögren's syndrome. Prevalence and clinical characteristics in a series of 320 patients. J Rheumatol 2002;29:726-30.

35. Wuttge DM, Lood C, Tufvesson E, Scheja A, Truedsson L, Bengtsson AA et al. Increased serum type I interferon activity in early systemic sclerosis patients associated with antibodies against Sjogren's syndrome antigens and nuclear ribonucleoprotein antigens. Scand J Rheumatol 2013;42:235-40. 